\title{
Mulheres Chefes de Famílias e Políticas Públicas: o Contraste com a Realidade no Bairro Getúlio Vargas (BGV), Rio Grande (RS)
}

\author{
Women Heads of Household and Public Policy: a Contrast Against Reality in \\ Getúlio Vargas District (BGV), Rio Grande (RS)
}

\author{
João Batista Flores Teixeira \\ Universidade Federal de Rio Grande \\ joao_sambora@hotmail.com
}

\section{Resumo}

No século XXI, a reestruturação econômica nacional possibilita que uma área do Bairro Getúlio Vargas (BGV), situado em Rio Grande (RS), faça parte do processo de expansão portuária. A área apresenta um importante número de famílias chefiadas por mulheres, assim o artigo objetiva refletir sobre questões referentes à cidadania, as políticas públicas e a chefia de família feminina na área de expansão, a partir de uma reflexão sobre cidadania e os planos nacionais de políticas para as mulheres.

Palavras-chave: Cidadania; mulheres chefes de família; políticas públicas.

\section{Abstract}

In the twenty-first century, Brazilian National economic restructuring allows that an area of Getúlio Vargas District (BGV), located in the city of Rio Grande (RS), take part in the process of port expansion. This area has a significant proportion of families headed by women, so the article discusses on the issues of citizenship, public policies and female headed households in the area in expansion, from a reflection on citizenship and the plans of the National policy for women.

Keywords: Citizenship; Women heads of family; Public policy. 


\section{Introdução}

Historicamente, a família tradicional brasileira constituiu-se como um núcleo patriarcal através dos papéis bem definidos, atribuídos aos homens/provedores e às mulheres/dona de casa. Esta família refere-se a uma realidade que há muito não da conta das transformações das atividades econômicas, das relações do capital e forças de trabalho e dos novos arranjos familiares observados na evolução da sociedade brasileira. Papéis que são desconstruídos historicamente tanto no plano material, do trabalho, como no político das lutas por autonomia e independência econômica.

Segundo Bruno Lautier (MONTALI apud Lautier, 2000, p. 55), a família brasileira cumpre um papel fundamental "de ajuste" ao "atenuar a carência de políticas sociais por parte do Estado e acolher os desempregados invisíveis socialmente", e além, a falta de políticas públicas eficientes, conduz a uma "espiral cumulativa onde são decompostas as estruturas familiares". Seja por políticas que tem como alvos os aposentados, como também as que cada vez mais tentam viabilizar a inserção de jovens e adultos no mercado de trabalho, tanto as que cumprem quanto as que não cumprem os seus papéis devem ser consideradas.

A reestruturação das famílias também possibilita que as mulheres desempenhem novos papéis em nossa sociedade, que se caracterizou no decorrer do século XX como machista e patriarcal e que no século XXI se transforma e mostra a importância de se considerar, não somente no âmbito da pesquisa acadêmica, mas no das políticas públicas, os novos papéis das mulheres, que há muito vem sendo um dos pilares sustentadores de nossa sociedade.

O objetivo principal do artigo é analisar as relações possíveis entre cidadania, políticas públicas e chefias de famílias femininas em uma área localizada no Bairro Getúlio Vargas (BGV) em Rio Grande (RS).

Acredito na "pesquisa atividade básica da ciência na sua indagação e construção da realidade" (MINAYO, 1993, p. 17), sendo o papel do pesquisador o de unificar o conhecimento para um melhor entendimento dela a 'realidade', estabelecer um objeto de pesquisa, buscando conhecimento desse, partindo de um ponto de vista. Este é um dos caminhos que a pesquisa pode utilizar para cumprir o seu papel social mais importante, não sendo elitizada, seja por intelectuais ou por quem tem acesso à informação que deve ser acessível a todos. Segundo o Geógrafo Paul Claval "Não existe mais critério racional que permita distinguir a ciência dos outros tipos de discursos. Todos devem ser tratados da mesma maneira" (CLAVAL,
2011, p. 307).

O recorte espacial da pesquisa é uma área de interesse da Superintendência do Porto do Rio Grande (SUPRG) localizada no BGV. A área foi delimitada junto à SUPRG, com os moradores representados pela Associação dos Moradores do Bairro Getúlio Vargas (AMABGV) e o Movimento Nacional de luta pela moradia (MNLM) que compreende uma faixa de 15 metros de largura paralela ao muro do parque automotivo do Porto Novo onde será construída uma avenida ligando a Rua Dom Pedro II até a BR-392 (MARTINS, et. al 2008).

A dinâmica populacional brasileira vem mudando ao longo dos anos. Evidência deste fato são os levantamentos de dados censitários realizadas pelo Instituto Brasileiro de Geografia e Estatística (IBGE). Segundo sinopse do censo demográfico de 2010, a população do Bairro Getúlio Vargas era de 4.867 homens (46,95\%) e 5.500 mulheres $(53,05 \%)$ totalizando 10.367 pessoas ali residindo. As mulheres são maioria, evidenciando a mesma tendência observada no restante do município de Rio Grande em que a população é de 94.983 homens $(48,16 \%)$ e 102.245 mulheres $(51,84 \%)$, totalizando na cidade 197.228 habitantes.

A maior expectativa de vida das mulheres eleva sua porcentagem no universo populacional, por tanto, é necessário um 'olhar' reflexivo em relação à elas, principalmente, as consideradas como chefes de família. No censo do IBGE do ano de 2000, 24,9\% das famílias brasileiras eram chefiadas por mulheres.

Estes indicadores fazem necessário o estudo de como estas mulheres conseguem o seu sustento, seja esse viabilizado por trabalho no circuito superior do capital ou no circuito inferior do capital, além de verificar em que condições acontecem. Também refletir sobre as políticas públicas necessárias e/ou existentes para aumentar a participação das mulheres no mercado de trabalho. Levando em consideração que por décadas a situação das mulheres em relação à família foi negligenciada pelos governos, pretendo, sem ser exaustivo, refletir sobre esta situação. Realizamos uma revisão bibliográfica e como instrumento de pesquisa utilizamos os dados do censo demográfico do IBGE e do primeiro Anuário das Mulheres Brasileiras e realizamos leituras dos Planos Nacionais de Políticas para as Mulheres (PNPM I e II).

$\mathrm{O}$ artigo esta estruturado em três partes. $\mathrm{Na}$ primeira parte discuto sobre concepções de cidadania e conceitos. Na segunda, relaciono as lutas sociais de mulheres e mulheres em lutas sociais e as políticas públicas brasileiras apresentando um breve histórico. $\mathrm{Na}$ terceira, apresento indicadores das famílias da área de estudo a partir do banco de dados do IBGE e do Nau e ao final teço algumas reflexões.

\section{J oão Batista Flores Teixeira}




\section{Discutindo Concepções de Cidadania e Conceitos}

De acordo com Santos (2008a), a discussão referente à cidadania necessita urgente revisão frente ao atual processo de globalização. Cidadania como conceito emerge na Inglaterra Vitoriana ${ }^{1}$ da necessidade de uma política de unidade proposta a princípio, pela elite burguesa da época. A segunda revolução industrial inglesa acontece em um momento histórico no qual disciplinar a mão de obra (HARVEY, 2011) era necessário como estratégia de Estado. Segundo Souki:

Para A. Marshall (...) sua preocupação era com a brutalização do homem, ele acreditava que em uma sociedade avançada o homem poderia ser um cavalheiro. (...) empíricas, apontavam para uma correlação positiva da divisão do trabalho $\mathrm{e}$ desenvolvimento de vida dos trabalhadores na Inglaterra. (...) quando os homens se percebem como homens e não como máquinas de produzir, convertem-se em cavalheiros, condição na qual aceitam progressivamente os deveres públicos e privados do cidadão. (SOUKI, 2006, p. 49).

A distinção desta categoria política como direito proveniente de deveres cumpridos e pré-estabelecidos acontece como forma de 'adequação' tanto por parte do Estado quanto por parte da população. No caso inglês, consideramos os "direitos adquiridos mediante lutas seculares" (SANTOS, 2008a). Portanto, cidadania é a consolidação, nesta sociedade destes direitos sociais e também destes deveres privados relacionados ao trabalho. Uma forma de comprometimento com o 'projeto' nacional idealizado.

Neste momento o trabalhador começa a ser reduzido a um apêndice do sistema vigente de produção industrial capitalista pelas elites que detêm os meios de produção. Esta concepção de cidadania, dominante de uma unicidade técnica (sistema capitalista) ideológica, na qual o trabalho trará 'dignidade' porque somente ele insere o trabalhador como cidadão na sociedade - com direitos e deveres adquiridos a partir do trabalho, exerceu forte influência no conceito de cidadania assimilado no Brasil. A contradição no discurso de cidadania no país difere da Inglaterra, pois ainda não conseguiu condições políticas e econômicas que garantam a cidadania para todos. Pelo contrário, a disputa histórica entre as classes médias, por privilégios mais que por direitos, e uma persistente negligência para com os pobres, evidenciam esta contradição (SANTOS, 2008a)

Porém, este tipo de política supracitada, levou aos países de economia capitalista avançada, no caso a Inglaterra, a deixar uma parcela muito grande de poder nas mãos dos trabalhadores. Alimentando assim, ainda mais as duas das principais geradoras de contradições do capitalismo: o capital-trabalho ${ }^{2}$ e o capital-limites da Natureza (HARVEY, 2011). O resultado foi que no século XX depois de duas guerras mundiais, e em meio a Guerra Fria acontece o ambiente favorável para a implementação do estado de bem estar social (Welfare State). Como resposta por parte dos Estados principalmente influenciados por Margaret Thatcher nos anos 1970 origina-se as políticas neoliberais ${ }^{3}$.

A articulação destas políticas globais em um cenário no qual as batalhas travadas para a tentativa da compressão tempo-espaço (HARVEY, 2011). Além da tentativa de baixa do custo de produção e mão de obra visando lucro pela classe capitalista levou as empresas a adotarem uma postura que definitivamente incorporaria a feminização do proletariado e da pobreza aos países do sul global:

As mulheres rurais do Sul global foram incorporadas à força de trabalho em todos os lugares, de Barbados a Bangladesh, de Ciudad Juarez a Dongguan. O resultado foi uma crescente feminização do proletariado, a destruição dos sistemas camponeses 'tradicionais' de produção autossuficiente e a feminização da pobreza no mundo. O tráfico internacional de mulheres para a escravidão doméstica e prostituição surgiu, na medida em que mais de 2 bilhões de pessoas, cada vez mais amontoadas em cortiços, favelas e guetos de cidades insalubres, tentava sobreviver com menos de dois dólares por dia. (HARVEY, 2011, p. 21).

A verticalidade e a consequente falta de horizontalidade (SANTOS, 2008b) deste tipo de tendência, por assim dizer, fez-se assimilar um conceito de cidadania e democracia, por exemplo, no Brasil e em outros lugares, "onde essas categorias nunca foram claramente definidas nem totalmente exercidas" (SANTOS, 2008a, p. 55).

O modo de produção capitalista atual é o urbano industrial (SANTOS, 2011). Logo, vivemos em uma sociedade de classes onde há espacialidade na divisão territorial do trabalho. Acredito que a melhor via explicativa para caracterizar o espaço urbano advém destas relações e não de abordagens consagradas que o tratam como organismo vivo (SANTOS, 2008) e legitimando todo tipo de

J oão Batista Flores Teixeira 
competição Darwiniana e Malthusiana, nem tampouco da abordagem bancária de formalidade e informalidade da mão de obra (HARVEY, 2011).

A cidade (ou espaço urbano) é entendida como um sistema do qual seus subsistemas, o circuito superior do capital (csc) e o circuito inferior do capital (cic) a integram. $\mathrm{O}$ csc "originou-se da modernização tecnológica e seus elementos mais representativos hoje são os monopólios." (SANTOS, 2008, p. 22). Enquanto o cic "formado por atividades de pequena dimensão e interessando principalmente aos pobres, é, ao contrário, bem enraizado e mantém relações privilegiadas com a região." (SANTOS, 2008, p. 22). A atual configuração do cic faz dele também o abrigo daqueles/as que não conseguiram se inserir no mercado de trabalho com carteira assinada, com direitos trabalhistas garantidos, com plano de saúde privado, educação de qualidade. No caso de nosso estudo, o $\mathrm{BGV}$ não possui população rural, por isso o foco no espaço urbano, criado e recriado pelo motor de transformação social conhecido pela divisão territorial do trabalho (SANTOS, 2008b).

Entendo que as novas utilizações teóricometodológicas hegemônicas nos estudos de gênero negligenciam por limites operacionais o conceito de chefes de família. Como abordado por Almeida e Veleda da Silva (2012), o Censo 2010 trabalhou, para fins de coletas de dados, com a concepção de arranjos familiares. Por ser uma questão de inextricabilidade, pois ainda é muito difundida a ideia de chefes de família e pelo fato das discussões em gênero serem muito matizadas (ALMEIDA e VELEDA da SILVA, 2012) não entrarei no debate para defender uma via que seja 'melhor'. Contudo pra fins de delimitação teórica utilizaremos a concepção de chefes de família:

As relações de gênero foram radicalmente transformadas $\mathrm{e}$ as rupturas familiares aumentaram na medida em que as mulheres se tornaram chefes de famílias e a tradicional classe trabalhadora masculina encontra-se reduzida ao status de uma subclasse descartável. (HARVEY, 2011, p. 125).

O nosso país viveu momentos de crises internacionais que refletiram nas estratégias e nos novos arranjos familiares. Com certeza, influindo do mesmo modo na caracterização da família tradicionalmente e religiosamente exposta de um casal e filhos, no qual os papéis definidos para o homem era o de prover o sustento familiar enquanto a mulher era um receptáculo para a reprodução biológica, educava os filhos e cuidava da casa. Esta concepção de família e de relações sociais não passa por nenhuma validação científica nem das mais pormenorizadas. Até porque, esta ideia na qual atribui ao homem uma imagem mitológica (como se tivesse super poderes) não considerava as contradições sociais. Por muito na história das migrações do Brasil, quando o homem saiu de seu estado pra ir procurar em outro industrializado emprego abandonou o lar e quem assumiu o papel historicamente definido para ele foi à mulher (DEMO, 2004).

Pode parecer utópico, mas é necessário se desfazer da concepção imposta de cidadania. Pois não diferente de outros conceitos, tendo uma carga ideológica sutil e intencionalmente marcada pelo discurso político do Estado, legitimador dos interesses dos ricos. Para tanto se deve entender a força e especificidade do lugar contra os efeitos perversos da globalização imposta (SANTOS, 2008a). A especificidade do indivíduo frente ao poder mitológico atribuído ao dinheiro. (SANTOS, 2008a). Além de compreender-se que a cidadania plena aparece quando a participação igualitária no mercado de trabalho e no cotidiano político da nação não advém de projetos políticos assistencialistas. Mas de projetos políticos nacionais de universalização da igualdade nestas esferas respeitando as especificidades de gênero, idade, raça, etnia, religião.

As lutas promovidas pelas mulheres (e por homens também) em movimentos ou movimentos de mulheres (MONTALI, 2000), principalmente para a redemocratização do Brasil, durante os anos finais da ditadura militar foram a prova disso. A prova de que os movimentos sociais de âmbito nacional quando envolveram as reivindicações de classe em conjunto com as de gênero em luta por uma cidadania plena acarretaram a verdadeira mudança política e social. A de efetivação da participação da mulher e das questões de gênero na agenda política nacional.

\section{Lutas Sociais de Mulheres e Mulheres em Lutas Sociais e as Políticas Públicas Brasileiras: Breve Histórico}

A identidade das lutas de gênero se confunde com a história recente do Brasil. A partir da constituição de 1988, e, graças aos movimentos feministas e às mulheres em outros movimentos sociais a desigualdade de gênero - diferença entre homens e mulheres, entra na agenda política nacional:

Sob o impacto da democratização e da luta de movimentos feministas e de movimentos de mulheres, desde os anos 80, tem

J oão Batista Flores Teixeira 
ocorrido, no Brasil, um processo gradual de incorporação da problemática das desigualdades de gênero pela agenda governamental. Com a importância crescente dos governos municipais, a partir da constituição de 88 , a redução das desigualdades de gênero passou a fazer parte da agenda dos governos locais. (FARAH, 2003, p. 1).

A partir da crise do Estado em 1990 (FARAH, 2003) o investimento em políticas sociais diminui gradual e significativamente. Soma-se a isso a tendência avassaladora da incorporação da doutrina neoliberal nos governos Fernando Collor, Itamar Franco e Fernando Henrique Cardoso (FHC). O avanço conseguido pelas lutas feministas e de gênero sofreu um duro golpe neste momento histórico e mediante esta espiral cumulativa a população lutava para no mínimo sobreviver (SANTOS, 2008a). A esfera política da época não imaginava ou fechava os olhos para o fato de que o "neoliberalismo é uma afronta ao significado ideológico do Estado". (HARVEY, 2011 p. 161).

Desconsiderando, brevemente, o fato de $o$ neoliberalismo defender "a promoção do individualismo e de uma ética de responsabilidade pessoal" (HARVEY, 2011, p. 161) em contrapartida da "diminuição das assistências sociais estatais" (HARVEY, 2011, p. 161). Esta crise era resultado, nos anos 1990, ainda da crise do petróleo (CP) de 1973 e da crise monetária e fiscal herdada dos governos militares. Depois do episódio, que ficou conhecido como milagre econômico (1969-1973), o Brasil passou por uma modernização econômica no qual os índices de emprego, salário e concentração de renda cresceram muito, ou seja, muitas pessoas se incorporaram ao csc, onde existe seguridade social e financeira, devido, as políticas desenvolvimentistas praticadas na época. A $\mathrm{CP}$ foi uma das primeiras barreiras enfrentadas por estes planos de desenvolvimento econômico, desencadeando nos anos 1980 uma série de tentativas frustradas, durante a ditadura militar, de controlar a inflação, acarretando no aumento da dívida externa, chegando em 1984 e 1985 a mais de $50 \%$ do produto interno bruto (PIB) ${ }^{4}$.

O resultado foi a crise fiscal dos anos 1990, marcada pela hiperinflação e início do intervencionismo externo de agências ${ }^{5}$ reguladoras como o Banco Mundial (BM) e o Fundo Monetário Internacional (FMI) no país. A dívida externa diminuiu por conta dos planos de austeridade (exemplo: corte dos gastos públicos) para salvar a economia. Note que estes planos eram para salvar as finanças do Estado e não a população. Até então as questões de investimentos para problemas sociais eram filantropia do setor privado. A primeira medida destes planos intervencionistas (e que há muito já vinha sendo praticado) foi a repressão salarial, tanto pública quanto privada, diminuição dos gastos públicos (educação, saúde, transporte, trabalho) "e, ao mesmo tempo, colocando poder do Estado a serviço do capital, em geral, e do investimento financeiro, em particular" (HARVEY, 2011, p. 141).

De um modo geral, a crise disciplina, ou melhor, (re)disciplina o trabalho, sendo a esperança da classe capitalista (visando o lucro) que o desemprego faça os trabalhadores aceitarem salários e condições de emprego menos favoráveis (HARVEY, 2011). Sônia Rocha aponta que o período de 1992 a 1999 "é marcado por uma forte incidência da pobreza, devida ao plano de estabilização de 1994, o Plano Real." (ROCHA, 2005, p. 106). As medidas políticas centradas na estabilização da moeda atrasaram a construção do Estado Social que se pretendia a partir de 1988. Acrescentando o fato da estabilização financeira com controle efetivo das dívidas públicas e da super inflação somente se concretizar nos anos 2000.

Uma vez iniciada a onda de privatizações dos anos 1990 o Estado se exime de todas as responsabilidades sociais do trabalho (o que acontece no privado não é de seu interesse), ou seja, não presta assistência dentro dos direitos trabalhistas devido à flexibilização da oferta de empregos (HARVEY, 1992), não se preocupa com demissões arbitrárias, desrespeito nas relações de trabalho como discriminação por gênero, raça, etnia e religião. Isso de fato é um erro, pois o que acontece no privado é sim de interesse do Estado (HARVEY, 2011). O trabalhador privado também elegeu o governo, entretanto, o Estado ao mesmo tempo em que incorpora a agenda neoliberal, recebe a recomendação do BM para incluir políticas públicas (PP) que focassem a problemática da feminização da pobreza investindo em "educação, saúde, serviços de extensão rural, infra-estrutura rural e urbana, segurança e geração de emprego e renda" (FARAH, 2003, p. 7).

Nota-se dois pontos essenciais: 1) O Brasil não havia feito investimentos ao longo da história que focassem a feminização da pobreza ou amenizar qualquer tipo de desigualdade, seja de raça, de religião, de etnia, quanto menos de gênero, sendo a assistência social considerada filantropia. 2) A política neoliberal adotada pelo Brasil até por conta de sua doutrina não se preocupava com contradições sociais, pois elas se resolveriam com a 'mão invisível' do mercado, a não ser quando queria desacreditar elas fato, pois uma vez que a descentralização na tomada

J oão Batista Flores Teixeira 
de decisões para as PP foi proposta, se recebeu com estranheza a decisão, pois "não havia um sistema e um aparato centralizado, cuja descentralização se reivindicasse" (FARAH, 2003, p. 6).

Existe na conceituação de feminização da pobreza outro limite operacional dentro das discussões de gênero. A crítica advém que "a disparidade de renda entre mulheres (ricas e pobres) tem crescido significativamente" (FARAH, 2003, p. 7). Ou seja, precisa-se "focalização dentro da focalização" (FARAH, 2003, p. 7), pois existem diferenças entre as próprias mulheres, requerendo uma abordagem que não seja geral e que seja específica pra cada grupo. A feminização da pobreza é um fenômeno, socialmente posto, capaz de produzir e reproduzir pobreza. $\mathrm{O}$ fato de uma classe acumular mais renda que as outras gera uma situação de desigualdade social. Entende-se a existência de diferentes grupos de mulheres (identidade) e formas de abordagem, mas o fenômeno social conhecido como feminização da pobreza não deixa de existir por isso.

Dentre outras perspectivas possíveis para o gênero a identificação do fenômeno social da feminização da pobreza é uma importante ferramenta de análise. Mas antes de prosseguir analiso o quadro histórico e geográfico aqui ensaiado. As políticas de redistribuição de renda não foram bem sucedidas, de um modo geral, no governo FHC, dada a tendência neoliberal de centralidade da política na estabilização da moeda (HARVEY et al., 2012). Porém, o governo do presidente Luís Inácio Lula da Silva (Lula) acabou aprimorando algumas delas (re)utilizando com outros nomes, vide o exemplo do programa bolsa família. Talvez alguns dos grandes trunfos do governo FHC foi o balanço fiscal e o controle da inflação. Contudo o preço social foi muito alto. Em Rio Grande o início da década, após sucessivas reestruturações econômicas durante as décadas anteriores, denota um alto índice de desempregados incidindo na participação de uma grande parcela da população no cic.

Entre os avanços mais significativos obtidos pelas políticas de gênero nos anos 2000 foi a consolidação da Secretaria de Política para as Mulheres (SPM) criada em 2003. O surgimento das Políticas Públicas para as Mulheres em 2007, a partir de mobilizações sociais.

A unificação destes debates acontece no I PNPM de 2004 e seguindo uma sequência histórica de sempre serem pensadas a nível nacional para beneficiar a todos e não determinadas situações regionais e especificidades, é que estas políticas partem do PNPM para o Governo Federal. As mulheres não lutam por condições especiais, mas sim por equidades no mercado de trabalho. Dificilmente, do meu ponto de vista, seria diferente, pois evidenciam o grau de cidadania específico que a mulher brasileira viveu pósanos 1970.

Os Planos Nacionais de Políticas para as Mulheres (PNPM) nascem da mobilização em todo território nacional de 200.000 mulheres, ocorrida no ano de 2007. Servindo como base para o Governo Federal na elaboração de Políticas Públicas, mas como o próprio plano descreve na segunda página "não traz benefícios só para as mulheres, é um plano que beneficia toda a sociedade". As propostas destas políticas devem ser atendidas no período compreendido entre 2007 e 2011.

Estes planos têm vínculo com a Secretaria de Políticas para as Mulheres criada em 2003, porém estão orientados diretamente para o governo. A sua efetivação somente será sucedida com a participação da União, governos estaduais e governos municipais. Por isto a importância destes PNPM's serem pensados no contexto do município do Rio Grande, especificamente no BGV.

O primeiro capítulo ${ }^{6}$ que trata a 'Autonomia Econômica e Igualdade no Mundo do Trabalho, com Inclusão Social', traça como em todo decorrer do plano, objetivos, metas e prioridades. Versa 'autonomia econômica e financeira das mulheres, considerando as dimensões: étnico- racial, geracional, regional e de deficiências' e que exista igualdade de gênero étnicoracial no trabalho. Em relação à 'mulher do campo', reconhecer as suas atribuições, assim como aquelas que vivem em comunidades tradicionais. Estender os direitos trabalhistas constitucionais às trabalhadoras domésticas, e de mesmo modo àquelas que vivem em situação de vulnerabilidade social, um dos pontos já alcançados, tendo em vista a efetivação da lei número $5859^{7}$.

A tendência buscada a partir da constituição de 1988 foi a de descentralização dos aparatos estatais de regulação social, ou seja, se consolidou a iniciativa de construir um Estado Social ${ }^{8}$ (HARVEY et al., 2012). Hoje, vemos a evolução destes no território, além de melhor distribuição, devido à própria estabilização financeira e capacidade de investimento do Governo Federal em políticas sociais. Porém, alguns municípios como Rio Grande, mesmo com todo este aparato institucional, carecem de ações efetivas nas políticas públicas de gênero. Trata tanto homens como mulheres de modo igual ${ }^{9}$. Nna prática (um erro quando consideramos a feminização da pobreza), diz que 'não trata por homogeneidade' no discurso e ignora bairros como o BGV, que na sua maioria são de pobres (cic) morando em áreas de ocupação e sem direito a cidade (HARVEY, 2011) ou a cidadania plena.

\section{J oão Batista Flores Teixeira}




\section{A Chefia Familiar Feminina no BGV}

Como vimos, a área passível da expansão portuária do Bairro Getúlio Vargas do município de Rio Grande foi delimitada através de intensas negociações e debates. Entender geograficamente onde acontece as lutas por melhores condições é pertinente, pois só conhecendo realmente o objeto/foco da pesquisa é que se pode estudar as questões socialmente ou empiricamente propostas.

A formação do $\mathrm{BGV}$ coincide com a industrialização do século XX de Rio Grande e investimentos que aconteceram na área portuária da cidade. As indústrias que se instalaram nos arredores e no BGV são as responsáveis por grande parte das ocupações profissionais dos habitantes do bairro. Tomando como lócus principal a área de expansão portuária do $\mathrm{BGV}$ e a pesquisa realizada pelos integrantes do Núcleo de Análises Urbanas (NAU) da FURG, publicada no ano de 2008, serão traçadas, quando possível, as relações entre os dados censitários do IBGE, arquivos e entrevistas do NAU para apresentar o contraste existente entre as propostas das políticas públicas e a realidade das famílias chefiadas por mulheres no BGV.

No BGV a expectativa de vida ${ }^{10}$ para as mulheres é de até 84 anos enquanto que para os homens é de apenas 74 anos de idade. Evidenciando um percentual maior de mulheres, que com suas aposentadorias e pensões ajudam no sustento da família. As mulheres chefes de família no BGV são também as que seguem vivendo com os filhos após uma separação, segundo Almeida e Veleda da Silva " $61 \%$ das famílias chefiadas por mulheres convivem com um ou três filhos enquanto que as chefiadas por homens o percentual é de 51\%" (ALMEIDA e VELEDA da SILVA, 2011, p. 9). Segundo o Anuário das Mulheres do Brasil de 2011, a participação das mulheres na renda mensal da família chegou a 45,5\% na região sul no ano de 2009 .

O BGV apresenta uma disparidade de rendas quando se compara as chefias de famílias de homens à de mulheres: a) menos de um salário mínimo: 40,24\% são mulheres para $24,12 \%$ homens; b) com um salário mínimo: 44,27\% são mulheres e 40,19\% homens; c) com mais de um até três salários mínimos: $68,41 \%$ são mulheres e $99,48 \%$ homens; d) com mais de três até seis salários mínimos: $7,4 \%$ são mulheres e $28,14 \%$ homens.

A situação laboral no bairro, referente à divisão sexual do trabalho, também apresenta valores desiguais nas chefias de família. As ocupações subdividem-se em: a) empregado com carteira assinada: $31,19 \%$ são mulheres e $60,29 \%$ de homens; b) empregados sem carteira assinada: $17,10 \%$ são mulheres e $44,21 \%$ homens; c) autônomo informal: 46,28\% são mulheres e 53,26\% homens; do lar 3,2\% são mulheres e nenhum ou números inexpressivos para homens; d) pensionista ou com licença médica: $28,17 \%$ são mulheres e 25,15\% homens; e) desempregados: $34,20 \%$ mulheres enquanto $10,5 \%$ homens.

Como se não bastasse as dificuldades das mulheres assumirem os papéis de chefes de família, suas colocações no mercado de trabalho são muito mais difíceis quando comparadas às condições dos homens. No BGV, por exemplo, o número de mulheres desempregadas é três vezes maior que os de homens, as mulheres com carteira assinada correspondem à metade do percentual comparativo. A análise dos dados referentes à chefia de família feminina também revela a relação com a ausência de companheiro. Somente $28 \%$ das famílias entrevistadas, nas quais as mulheres têm companheiro se dizem chefe de família, enquanto para homens este percentual sobe para $74 \%$. "Essa relação demonstra o quanto a chefia masculina ainda é considerada como a 'correta' para o arranjo familiar, já que somente na ausência de um cônjuge/companheiro masculino as mulheres colocaram-se na responsabilidade familiar" (ALMEIDA, VELEDA da SILVA e TEIXEIRA, 2012, p. 13).

(...) eu e a minha filha moramos só. Eu sou a responsável pela casa, eu vendi a minha casa. Quando eu me separei eu vendi tudo porque tem horas que tu precisas da tua paz, então vende que (...) veio a minha parte sem problema nenhum. Eu moro de aluguel né, moro no bairro de aluguel. (Secretária da $A M A B G V, 2011)$.

A baixa escolaridade entre os chefes de família evidencia a vulnerabilidade social dos moradores do $\mathrm{BGV}, 65 \%$ dos homens e $64 \%$ das mulheres possuem o ensino fundamental incompleto. Enquanto as mulheres estão em situação de maior risco social, sendo que elas representam o maior percentual de analfabetas e os homens apresentam maior percentual de ensino médio completo, ou seja, existe uma situação clara de desigualdade social devida a escolaridade e possibilidade de acesso à melhores condições de emprego não suficientemente atendidas pelas políticas públicas:

(...) sempre gostei dessa coisa de buscar políticas públicas. Hoje tem este nome, porque antigamente eu não entendia o quê que era. Eu queria que a menina tivesse orgulho de ser negra, como eu tenho

João Batista Flores Teixeira 
orgulho de ser negra. Mas pra tu ter orgulho, tu tem que ter conhecimento da tua história e as pessoas é o que faltam pra elas: conhecer, ter a profundidade, sou negra com muito orgulho e não é o que passa, a escola não passa isto né. Eu digo que hoje recém são políticas novas que tudo ainda ta muito lentinho. (Secretária da $A M A B G V, 2011)$.

A divisão sexual do trabalho e das atividades relacionadas à família, tradicionalmente concebida, acarretam em sobrecarga de atividades para as mulheres. Mais filhos permanecem com as mulheres chefes de famílias do que com os homens, cerca de $61 \%$ para as mulheres, enquanto que para os homens o percentual é de $33 \%$ :

A maior presença de fillhos nos domicílios de mulheres chefes de família imputa uma sobrecarga nos afazeres e nas responsabilidades domésticas oriundas da divisão sexual do trabalho, levando a uma maior exploração do trabalho feminino, através da dupla, tripla ou mesmo quádrupla jornada de trabalho. (ALMEIDA, VELEDA da SILVA E TEIXEIRA, 2012, p. 13).

A presença no PNPM de uma categoria que garanta a inclusão do emprego doméstico com carteira assinada e jornada de trabalho acessível não incluiu as mulheres domésticas no BGV que continuam vivendo uma cidadania parcial. As jornadas de trabalho injustas destinadas às mulheres, inevitavelmente impostas pela flexibilização das condições do trabalho associadas à falta de uma esfera local política, não faço alusão ao sindicato, mas a um órgão que consolide o Estado social com ações locais. Catalisa o efeito produtor e reprodutor da feminização da pobreza:

Também era mãe solteira, porque na realidade a gente tinha um pai, mas muito tempo separada ela assume igual desse casamento porque ela foi mãe muito nova, mais duas filhas que não eram dela mas ela cuida e a minha mãe sempre exigiu isso de nós. E aí passa a idade, a fase adulta que passa a tu não aproveitar todas as oportunidades. (...) embora pobre, tu ta acostumada com uma situação diferenciada e passa pra outro lugar que tu vê uma situação totalmente diferente. (Secretária da AMABGV, 2011).
A participação no csc no $\mathrm{BGV}$ é seletiva. A diferença de acessibilidade a esse circuito caracterizado pela seguridade do trabalho com carteira assinada, plano de saúde e condições de emprego não sazonal é sexual, pois $42,94 \%$ são homens e $33,68 \%$ são mulheres.

Os debates referentes à expansão portuária de Rio Grande que atingiram os moradores do bairro ocasionando discussões tanto com a prefeitura quanto com a SUPRG referentes à área do lugar onde vivem é evidência do atual período nacional de promoção do crescimento econômico (HARVEY et al., 2012). A expansão industrial associada à valorização do solo urbano e consequente especulação imobiliária são sinais de progresso, para o Estado.

Contudo, as populações pobres, como no presente artigo o caso do BGV e especialmente as mulheres chefes de famílias, que não têm acesso a condições financeiras são comumente marginalizados pelo sistema. Para que o 'progresso' se concretize essa área de expansão industrial precisa ser 'higienizada' da presença dos pobres (HARVEY et al., 2012), como já aconteceu nos anos 1960 e 1970 no BGV. Portanto, o caráter excludente do capital em relação ao espaço urbano deve ser sanado com a construção, como na proposta de Hannah Arendt "de uma comunidade política para que o sujeito tenha direitos, de uma esfera pública que valorize as opiniões e torne suas ações eficazes" (HARVEY et al., p. 78). O Brasil economicamente vem modernizando a sua economia devido à estabilidade do 'Plano Real' em meados dos anos de 1990 e o Plano de Aceleração do Crescimento o PAC dos anos 2000, como consequência as microestruturas da economia formada pelos municípios, no caso Rio Grande, sofrem com estas mudanças que não atingem somente a esfera física, mas também a esfera do humano nas relações sociais quando tratamos as mutações que os municípios vêm sofrendo em suas estruturas.

\section{Reflexões Possíveis}

As abordagens de gênero evitam a utilização dos termos chefes de família e feminização da pobreza, devido por um lado, a carga ideológica de reprodução de uma sociedade patriarcal e por outro lado devido a necessidade de um foco não generalista. Contudo os atrasos teóricos que algumas discussões podem trazer, não acompanhando a esfera de decisões políticas, pode gerar um lapso de ação que a investigação científica não deve acompanhar e a consequente disseminação de eufemismos linguísticos.

A situação da mulher na sociedade do século XXI é reveladora das esferas: política, econômica e cultural. 
E o entendimento destas é possível a partir de uma abordagem que considere a sua materialidade e também o seu simbolismo. Representados pelas transformações do espaço geográfico, possíveis graças ao motor de transformação que é a divisão territorial do trabalho. Por isso o presente artigo apresenta um ensaio de como mudanças econômicas, políticas e sociais devidas à modernização econômica recente de nosso país têm relação com as desigualdades sociais que as chefes de família no BGV sofrem não conseguindo alcançar a cidadania plena.

Se considerarmos as desigualdades existentes, no que tangem a chefia de família feminina no BGV, quando tratado a questão da inserção destas 'provedoras' no mercado de trabalho sendo que muitas das possibilidades das políticas públicas não as ajudam a ingressar em empregos no csc, que além de autonomia geram sustento para suas famílias. Assim, as políticas públicas quando não cumprem o seu propósito podem deixar de existir. Não que seja o caso, mas os PNPM' s devem cumprir os seus objetivos, porque sem esses a participação das mulheres no csc se tornará cada vez mais difícil, discriminatória e seletiva. E a mobilidade social não existirá.

É importante entender que uma vez submetida à lógica de mercado, por isso mercado de trabalho, invariavelmente existirão desigualdades nas ofertas e possibilidades de acesso. Não se trata de um posicionamento simples: devemos optar por uma esfera política local que de conta das especificidades locais, ou continuar do modo que está. E caso continue 'tudo igual' o mercado de trabalho continuará exigindo profissionais capacitados e bem preparados, e se o Estado mesmo com políticas públicas, deixar de auxiliar as classes pobres à alcançarem a cidadania plena em específico as mulheres chefes de família que se encontram nesta situação as desigualdades sociais que vivemos no Brasil serão ainda maiores.

1 A era Vitoriana compreende o período de 1837 - 1901 na Inglaterra, do reinado de Vitória. Ver dicionário Aurélio da Língua Portuguesa.

2 Para o presente artigo somente esta contradição será abordada.

3 "Minha opinião é que se refere a um projeto de classe que surgiu na crise dos anos 1970. Mascarada por muita retórica sobre liberdade individual, autonomia, responsabilidade pessoal e as virtudes da privatização (...) legitimou políticas draconianas para restaurar e consolidar o poder da classe capitalista"
(HARVEY, 2011, p. 16).

4 Fonte Ministério da Fazenda.

5 Ambas legitimadoras das políticas neoliberais européias e dos EUA.

6 Selecionado como preferencial para o presente artigo.

$7 \quad 11$ de dezembro de 1972.

8 "(...) sob a ideia de que a democracia se consolida com base no discurso de direitos humanos combinado com a lógica de mercado, o que limita a própria ideia de humano." (HARVEY et al. 2012, p. 80).

9 "Falar em reduzir desigualdades de gênero não significa negar a diversidade." (FARAH, 2003, p. 1).

10 A expectativa de vida ao nascer em 2009 segundo o IBGE é de 71, 9 anos para os homens e 78, 7 anos para as mulheres na região sul.

\section{Referências}

ALMEIDA, Andressa.; VELEDA da SILVA, Susana Maria. Trabalho e chefia familiar feminina: o caso do processo de expansão portuária no Bairro Getúlio Vargas - Rio Grande (RS). XXX Encontro Estadual de Geografia. Anais do XXX Encontro Estadual de Geografia, Erechim (RS), 2011, p. 1 - 10

ALMEIDA, Andressa Cristiane Colvara; VELEDA da SILVA, Susana Maria. Trabalho, moradia e chefia familiar: o caso do processo de expansão portuária no Bairro Getúlio Vargas - Rio Grande (RS). Revista Latino Americana de Geografia e Gênero, v. 3, n. 2, p. $138-149,2012$.

ALMEIDA, Andressa Cristiane Colvara; VELEDA da SILVA, Susana MARIA; TEIXEIRA, João Batista Flores. TRABALHO, GÊNERO E OS CIRCUITOS DA ECONOMIA URBANA: O CASO DAS ÁREAS DE EXPANSÃO PORTUÁRIA DO PORTO DE RIO GRANDE (RS). 2012. [No Prelo].

CASA CIVIL. Lei Maria da Penha, Lei Número 11340, de 6 de agosto de 2006. [Acessível em http://www.planalto.gov.br/. Acessado em Julho de 2012].

João Batista Flores Teixeira 
CASA CIVIL. Dispõe sobre a profissão de empregado doméstico e dá outras providências, Lei Número $\quad 5859 . \quad$ Acessível em http://www.planalto.gov.br/. Acessado em Julho de 2012.

CLAVAL, Paul. Epistemologia da Geografia. Florianópolis: Editora da UFSC, 2011.

DEMO, Pedro. Dureza: pobreza política de mulheres pobres. Campinas/SP: Autores Associados, 2005.

Departamento Intersindical de Estatística e Estudos Socioeconômicos (DIEESE). ANUÁRIO DAS MULHERES BRASILEIRAS (AMB). São Paulo/ Brasília: e Secretaria de Políticas para as Mulheres (SPM), 2011.

FARAH, Marta. F. S. Políticas públicas e gênero. Disponível em: [Disponível em http://ww2.prefeitura.sp.gov.br//cidadania/conselhos_e _coordenadorias/coordenadoria_da_mulher/Politicas_

Genero_2.pdf. <Acesso em dezembro 2011>.

HARVEY, David. O enigma do capital: e as crises do capitalismo. São Paulo: BOITEMPO. 2011.

HARVEY, David. Condição Pós-Moderna. $6^{\text {a }}$ edição. São Paulo: LOYOLA, 1992.

HARVEY, David (et al.). Occupy. São Paulo: BOITEMPO - CARTA MAIOR, 2012.

INSTITUTO BRASILEIRO DE GEOGRAFIA E ESTATÍSTICA (IBGE). Censo demográfico. [Disponível em www.ibge.gov.br]. <Acesso em outubro de 2011>.

INSTITUTO BRASILEIRO DE GEOGRAFIA E ESTATÍSTICA (IBGE). Perfil Das Mulheres Responsáveis por Domicílios no Brasil 2000. Rio de Janeiro: IBGE, 2004.

MARTINS, Cesar Augusto (et al.). Georeferenciamento do Bairro Getúlio Vargas: delimitação topográfica com implantação de marcos físicos no terreno e mensuração da área atingida pela expansão portuária. Relatório BGV-NAU Rio Grande, FURG, 2008.

MINAYO, Maria Cecilia (Org.) (et al.). Pesquisa Social. Teoria, método e criatividade. $10^{\mathrm{a}}$. Ed. Petrópolis: Editora Vozes, 1993.
Ministério da Fazenda. Evolução da Dívida Externa e da Dívida Pública. Brasília (DF). [Disponível em http://www.fazenda.gov.br/.pdf]. <Acessado em Julho de $2012>$.

MONTALI, Lilia. Família e Trabalho na Reestruturação Produtiva: Ausência de Políticas Públicas de Emprego e Deterioração das Condições de vida. Revista Brasileira de Ciências Sociais, v. 15, n. 42, 2000, p. $55-71$.

OLIVEIRA de FRANCISCO, Maria Luíza. Geografia de Gênero e Trabalho Familiar: Algumas Considerações. Revista Latino Americana de Geografia e Gênero, v. 2, n. 1, p. 27 - 36, 2011.

PLANO NACIONAL DE POLÌTICAS PÚBLICAS PARA AS MULHERES (PNPM) I. Brasília: Secretaria de Políticas para as Mulheres (SPM), 2005.

PLANO NACIONAL DE POLİTICAS PÚBLICAS PARA AS MULHERES (PNPM) II. Brasília: Secretaria de Políticas para as Mulheres (SPM), 2008.

ROCHA, Sonia Maria Rodrigues da. Pobreza no Brasil: Afinal do que se trata? Terceira edição. Rio de Janeiro: Editora FGV, 2006.

PACHECO, Juliana Thaisa Rodrigues. Demandas habitacionais de famílias mono parentais com responsabilidade feminina e as políticas públicas municipais desenvolvidas pela PROLAR entre 2004 à 2007 em Ponta Grossa - PR. Revista Latino Americana de Geografia e Gênero, v. 1, n. 2, p. 233 $-244,2010$.

SANTOS, Milton. O Espaço Dividido. 2a . Edição. São Paulo: EDUSP, 2008.

SANTOS, Milton. Por uma outra globalização: do pensamento único ao pensamento universal. $15^{\mathrm{a}}$ edição. Rio de Janeiro: RECORD, 2008a.

SANTOS, Milton. A Natureza do Espaço: Técnica e Tempo, Razão e Emoção. $4^{\text {a }}$ edição, quarta reimpressão. São Paulo: EDUSP, 2008b.

SOUKI, Lea Guimarães. A atualidade de T. H. Marshall no estudo de cidadania no Brasil. Civitas, v. 6, n. 1, p. $39-48,2006$.

Recebido em 29 de dezembro de 2011. Aceito em 23 de novembro de 2012. 